\title{
Rotura vesical espontánea en paciente senil con prolapso genital
}

\author{
Pérez Romero N, Gómiz León JJ, Alonso Prieto MA, Corral Rosillo J, Galante Romo I, \\ Silmi Moyano A.
}

Servicio de Urología. Hospital Clínico Universitario San Carlos. Madrid.

Actas Urol Esp. 2008:32(4):464-466

\begin{abstract}
RESUMEN
ROTURA VESICAL ESPONTÁNEA EN PACIENTE SENIL CON PROLAPSO GENITAL

Son múltiples y diversas las causas etiológicas de la rotura vesical. Los politraumatismos (accidentes de tráfico), el traumatismo directo abdominal, cerrado o abierto, y las lesiones yatrogénicas (cirugía abierta, endocirugía, cateterismo uretral) figuran entre las más frecuentes; sin embargo, la rotura vesical no siempre exige para su producción un enérgico, violento, directo y evidente agente externo que la provoque. En el caso que a continuación se comunica, la rotura vesical extraperitoneal tuvo su origen en un leve traumatismo perineal ocasionado al sentarse la paciente, la cual presentaba y padecía desde mucho tiempo atrás un cistocele grado III/IV acompañado de prolapso uterino.

Palabras clave: Perforación espontánea Vejiga. Prolapso genital.

\section{ABSTRACT \\ SPONTANEOUS EXTRAPERITONEAL BLADDER PERFORATION IN AN ELDERLY PATIENT WITH GENITALIA PROLAPSE}

There are many etiologic reasons which explain the bladder perforation. Bladder injuries happen most commonly in poli-traumatisms (traffic accident), blunt trauma, penetrating injury and iatrogenic injury (surgery, laparoscopic...). However, there is not always a vigorous, direct, extern and blunt agent causing the rupture. In the case reported the extraperitoneal bladder rupture started after a smooth perineal injury caused when the patient seated down. The patient already suffered from a cystocele III/IV plus uterine prolapse for a long time ago.

Keywords: Spontaneous perforation. Bladder. Genital prolapse.
\end{abstract}

$\mathrm{E}$ trabajo remitido expone el caso clínico de una rotura vesical. Se complementa mediante discusión, con una revisión de esta patología, atendiendo a sus tipos, etiología, métodos diagnósticos y abordajes terapéuticos.

\section{CASO CLÍNICO}

Paciente de 96 años con antecedentes personales de Diabetes Mellitus no insulinino dependiente y prolapso uterino grado IV.

Acude al servicio de urgencias tras caída accidental cuyo mecanismo consiste en un movimiento de sedestación brusco. La paciente refiere dolor y sangrado genital. En el momento de la caída refiere tener una importante replección vesical.
A la exploración se objetiva un prolapso uterino grado IV con laceración de mucosa uterina sin otros hallazgos de interés salvo hematuria leve en la primera micción espontánea que aclara en micciones posteriores.

Se realizan como pruebas complementarias: analítica de sangre y orina que no revelan alteraciones significativas y ecografía abdominal donde no se describen alteraciones de interés.

La paciente queda ingresada en observación y presenta en las primeras doce horas empeoramiento clínico y analítico. Comienza con importante dolor abdominal, en región suprapúbica que aumenta a la palpación objetivándose signos de defensa abdominal. Presenta disminución de diuresis por sonda vesical. 
Analíticamente se demuestra leucocitosis e insuficiencia renal aguda sin signos de anemización.

Ante este empeoramiento se realiza TAC con contraste y cistografía (Figs. 1 y 2) objetivándose fuga del contraste a nivel de cara posterior vesical, sin líquido libre entre asas intestinales, hallazgos compatibles con perforación vesical extraperitoneal. La punta del catéter de Foley se encuentra extravesical.

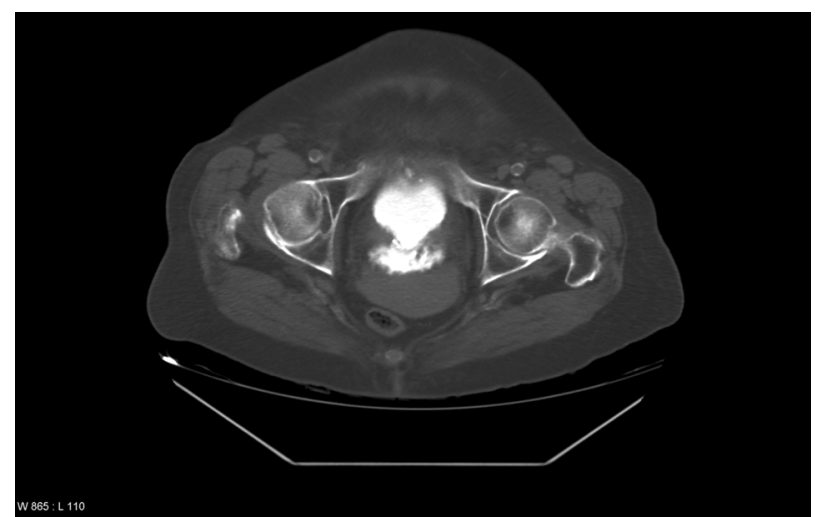

FIGURA 1

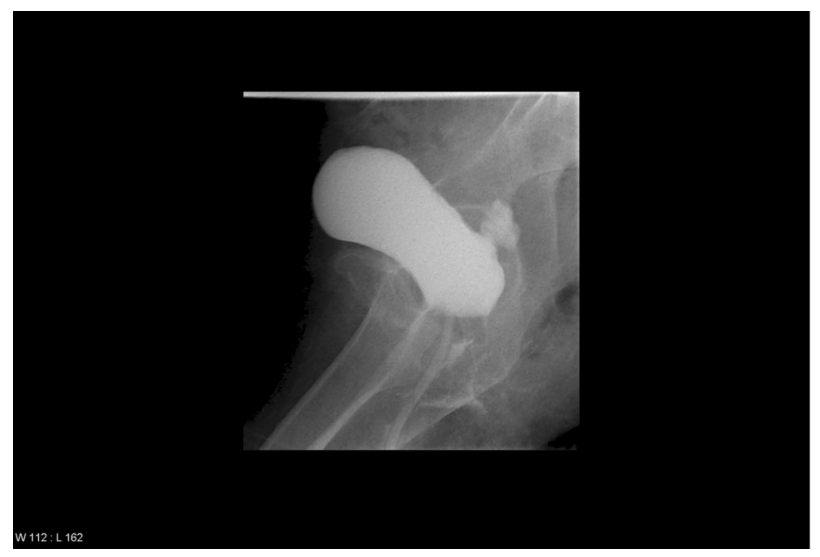

FIGURA 2

Tras recolocar la sonda intravesical, la paciente comienza con abundante diuresis con orina clara y cede el cuadro de dolor abdominal. Con tratamiento médico de soporte y antibioterapia se normalizan las alteraciones analíticas.

A los diez días se retira la sonda vesical tras comprobación cistográfica de ausencia de fuga.

\section{DISCUSIÓN}

Mientras que en la edad infantil la vejiga adopta una situación principalmente intra-abdominal, en el adulto ocupa el denominado compartimiento anterior de la pelvis menor; el uraco la fija al plano músculo- aponeurótico abdominal anterior, quedando rodeada antero-lateral y caudalmente por tejido adiposo y conectivo laxo, mientras el peritoneo parietal la recubre cranealmente, replegándose en la mujer, posteriormente, sobre el útero para formar el espacio o saco vesico-uterino; la superficie externa posterior-inferior de la vejiga, así como la uretra, reposan sustentándose en la pared vaginal anterior. El pubis, las ramas isquiopubianas, los ligamentos pubianos y umbilical y la pared anterior del abdomen protegen exteriormente la vejiga, cuyas paredes inferolaterales se relacionan con los músculos obturadores internos y su fascia en la que se fija el músculo elevador del ano y el coccígeo formando éstos el suelo pelviano la cual, en estado de replección, distendida, adopta forma esférica para salir de la pelvis y separar el peritoneo que recubre su cúpula de la parte posterior de la pared anterior del abdomen, ofreciendo a éste nivel una menor resistencia y mayor vulnerabilidad $^{1}$. Según la porción de la vejiga donde se produzca solución de continuidad, anatómicamente se clasifica la rotura o perforación vesical en "intra" "extra" o "intra-extraperitoneal". Las extraperitoneales suelen localizarse en la cara anterior, próximas al cuello vesical, generalmente puntiformes o parciales, mientras que las intraperitoneales lo hacen a nivel de la parte posterior de la cúpula y ofrecen un aspecto lineal ${ }^{2}$.

Excluidas las etiologías traumática y yatrogénica, porcentualmente predominantes (95\%), han sido reportados casos excepcionales de rotura vesical de causa obstétrica $^{3,4}$, relacionadas con patología de la pared vesical: divertículos ${ }^{5,6}$, neoformación ${ }^{7}$, de naturaleza rádica ${ }^{8}$, infección micótica ${ }^{9}$, bacteriana ${ }^{10}$, tuberculosa ${ }^{11}$ o espontánea primaria ${ }^{12,13}$, en portadores de catéter uretral $^{14}$, por hiperingesta alcohólica y sobredistención vesical ${ }^{15}$ o abuso de $\operatorname{drogas}^{16}$.

El adjetivo "espontáneo" se emplea, desde que fuera, introducido en la nosología urológica ${ }^{17}$ como equivalente a la exclusión etiológica traumática o yatrogénica en la causa inmediata desencadenante de la rotura vesical, la cual puede ser tanto extra como intraperitoneal, siendo la incidencia de ésta última algo mayor; sin embargo, aunque no siempre pueda concretarse con exactitud la causa de lesión "espontánea”, generalmente pueden reconocerse factores propios o alteraciones de la pared vesical asociadas, no necesariamente, con patología obs- 
tructiva vésico-uretral intrínseca o extrínseca, así como traumatismos que por su levedad puedan quedar obviados en la anamnesis.

La distensión vesical, el aumento de presión intracavitaria, alteraciones patológicas de la pared (inflamación, neoplasias, fibrosis) o involutivas relacionadas con la edad, ultra estructuralmente reconocibles en el músculo liso y en determinados elementos del estroma ${ }^{18}$ coadyuvantes de una menor resistencia y mayor vulnerabilidad, son, entre otros, factores que se involucran en la rotura vesical. El prolapso de compartimiento anterior y medio puede propiciar lesión de los órganos afectados, en concreto de la vejiga, cuya incidencia en la práctica debe ser mayor que la que refleja la literatura urológica, particularmente cuando son de larga evolución, no tratados, y se asocian con ulceras de decúbito en la pared anterior de la vagina ${ }^{19}$, o bien por simple efecto de la súbita hiperpresión intravesical sobrevenida al sentarse la paciente sobre una superficie dura.

La clínica de la rotura vesical incluye un cuadro sindrómico variable que va desde un leve dolor hipogástrico hasta una situación de abdomen agudo. La hematuria en el caso de perforación extraperitoneal está presente en el 90\% de los casos.

La cistografía de relleno realizada con suficiente volumen de contraste infundido (200-250 cc), proyecciones oblicuas y placa post-vaciado, así como la cistografía TAC, la cual ofrece una sensibilidad de $95 \%$ y especificidad de $100 \%{ }^{20}$, son los métodos de elección para el diagnóstico por imagen y categorización concreta de la rotura.

En los casos de perforación extraperitoneal, el tratamiento conservador presenta excelentes resultados en casos seleccionados. Se realiza drenaje vesical durante 2-3 semanas con comprobación cistográfica de la reparación vesical previa a la retirada del catéter.

\section{REFERENCIAS}

1. Bastable JR, De Jode LR, Warren RP. Spontaneous rupture of the bladder . Br J Urol. 1959 Mar;31(1):78-86.

2. Gonzalez Tuero J; Pérez Lacort, L; Fernández Madrigal, F; Junquera Villa, JM. Traumatismos vesicales: roturas y perforaciones no yatrogénicas. Nuestra experiencia en veinte años Actas. Urol. Esp. 1985 Sep-Oct;9(5):421-428.

3. Linke CA, Linke CL, Worden AC. Bladder and urethral injuries following prolonged labor. J Urol. 1971 May;105(5):679-682.

4. Raghavaiah NV, Devi AI. Bladder injury associated with rupture of the uterus Obstet Gynecol. 1975 Nov;46(5):573-576.
5. Castiñeiras Fernández J, López Muñóz A, Cabello P, Varo Solís C, Sánchez del Pino MJ, Rodríguez-Rubio Vidal F. Rotura vesical extraperitoneal espontánea por patología diverticular “. Actas Urol Esp. 1989 Jul-Aug;13(4):276-280

6. Keeler LL, Sant GR. Spontaneous rupture of a bladder diverticulum. J Urol. 1990 Feb;143(2):349-351.

7. Valero Puerta JA, Medina Pérez M, Monteagudo Parreño A, Enamorado Interiano R, Valpuesta Fernández I, Sánchez González M. Perforación vesical extraperitoneal espontánea por carcinoma vesical. Actas Urol Esp. 2000 Nov-Dec;24(10):817-819.

8. Baseman, AG; Snodgrass, WT. Repeat spontaneous bladder rupture following radiation therapy. J Urol. 2003 Dec;170(6 Pt 1):2417.

9. Fernández Borrell A, Peinado Ibarra F, Fernández Arjona M, Gómez-Sancha F, Muñoz Vicente E, Teba Del Pino F, Romero Tejada JC, Pereira Sanz I. Perforación vesical espontánea secundaria a candidiasis vesical. Actas Urol Esp.1997 Jul-Aug; 21(7):701-704.

10. Rodríguez Rodríguez A, Vendrell R, Luque P, López-Alvarado S, Alcaraz A, Carretero P. Perforación vesical espontánea secundaria a cistitis bacteriana. Causa de abdomen agudo en ancianos diabéticos Actas Urol. Esp, 1995, 19(5):393-397.

11. Vallejo Gil C, Palacio EV, Reig Ruiz C, Raventos Busquets C, Morote Robles J, Soler Roselló A. Rotura vesical espontánea secundaria a tuberculosis urinaria Actas Urol Esp. 1994 Sep;18(8): 829-832.

12. Losada Guerra JL. Rotura vesical extraperitoneal espontánea Arch Esp Urol, 1994, 47(6):627-629.

13. González Chamorro F, Moncada Irribarren I, Herranz Amo F, Díez Cordero JM, Escribano Patiño G, Lledó García E, Rodríguez Fernández E, Hernández Fernández C. Rotura vesical espontánea sin causa aparente; una presentación clínica particular “. Arch. Esp Urol.1995,48(8):848-850.

14. Capitán Manjón C, Tejido Sánchez A, Piedra Lara JD, García Peñalver C, Rosino Sánchez A, Palomar Estrada A, Muyor Piñero C, Leiva Galvis O. Rotura vesical extraperitoneal espontánea. Presentación de un caso. Actas Urol Esp.2001,25 (4): 291-294.

15. Guinda Sevillano C, Fernández Rosaenz J, Arnaiz Esteban F, Pérez Arbej JA, Martínez Pérez E, Nogueras Gimeno MA, Espuela Orgaz R. Rotura vesical espontánea. A propósito de un caso. Actas Urol Esp.1993,17(5):338-340.

16. Marshall GA, Dixon CM, McAninch JW. Substance abuse-related spontaneous bladder rupture: report of 2 cases and review of the literature J Urol.1991 Jan;145(1):135-137.

17. Stone E. Spontaneous rupture of the urinary bladder. Arch. Surg, 1931,23:129-131. 18. Lepor H, Sunaryadi I, Hartano V, Shapiro E. Quantitative morphometry of the adult human bladder. J. Urol, 1992 Aug;148(2 Pt 1):414-417.

19. Miller CG, Marshburn PB, Talber LM, Tucker MS. Blunt trauma of uterovaginal and vesical prolapse with associated bladder rupture. J. Urol, 1990, 144( 2 Pt 1 ):348-350.

20. Deck AJ, Shaves S, Talner L, Porter JR. Computerized tomography cystography for the diagnosis of traumatic bladder rupture. J. Urol, 1990, 164(1):43-46.

Correspondencia autor: Dra. N. Pérez Romero

Servicio de Urología. Hospital Clínico Universitario San Carlos Profesor Martín Lagos, s/n - 28040 Madrid

Tel: 913303000 - 913303001

E-mail: natape@hotmail.com

Información del artículo: Nota clínica

Trabajo recibido: septiembre 2006

Trabajo aceptado: julio 2007 